\title{
Career choice narratives: engineering personality types?
}

\author{
James Moir
}

Abertay University, Dundee, UK

\begin{abstract}
Psychological models have portrayed career choice narratives in terms of personality dimensions. In contrast to this approach, the research reported on in this study employs a conversation analytic perspective in order to examine the deployment of career choice narratives in terms of intelligibility and accountability. Engineering students on a degree programme were interviewed about their career choice. The responses given are examined for the display of membership categories in terms of personality characteristics commonly associated with engineering. Rather than revealing a psychological construct of a personality, the responses are considered as themselves being engineered to address the display of rational agency and deliberation in arriving at a career choice.
\end{abstract}

Keywords: Holland, career, choice, membership, categories

\section{Holland's theory of career personalities}

Psychological models of career choice have often mirrored lay discourse in terms of a structural or 'personality-matching' approach. Psychometric techniques have been used to predict career choices on the basis of personality assessments. For example, Holland's (1959, 1966, 1973, 1985, 1997) theory had dominated the field amongst structural approaches, in which there are six main personality types along with their corresponding environments. The theory has been refined over a number of years, although its basic principles have remained unaltered. In Making Vocational Choices, Holland (1985, pp. 2-4) reiterates the four axioms around which his theory is organised:

1. In westernised culture, most people can be categorised as one of six types: realistic, investigative, artistic, social, enterprising, and conventional.

2. There are six model environments that correspond with the above personality typology. 
3. People search for environments that let them express their personality type in terms of attitude and values, as well as adopting agreeable work roles.

4. Behaviour is determined by an interaction between personality and work environment.

Holland derived his career personality typology from the factor analysis of responses to several interest inventories gathered over time. Holland (1985, pp. 1923) describes the types in terms of interests and aversions as follows:

Realistic types have a preference for activities that entail the explicit ordered, or systematic, manipulation of objects, tools, machines and animals; and an aversion to educational or therapeutic activities (e.g., mechanic, farmer, lorry driver).

Investigative types have a preference for activities that entail observational, symbolic, systematic, and creative investigation of physical, biological, and cultural phenomena in order to understand and control such phenomena; and an aversion to persuasive, social, and repetitive activities (e.g., scientist, designer, engineer).

Artistic types have a preference for ambiguous, free, unsystematised activities that entail the manipulation of physical, verbal, or human materials to create art forms of products; and an aversion to explicit, systematic, and ordered activities (e.g., artist, writer, musician).

Social types have a preference for activities that entail the manipulation of others to inform, train, cure, or enlighten; and an aversion to explicit, ordered, systematic activities involving materials, tools, or machines (e.g., teacher, nurse, counsellor).

Enterprising types have a preference for activities that involve the manipulation of others to attain organisational goals or economic gain; and an aversion to observational, symbolic, and systematic activities (e.g., politician, salesperson, buyer).

Conventional types have a preference for activities that entail the explicit ordered systematic manipulation of data such as keeping records etc.; and an aversion to ambiguous, free, exploratory, or unsystematised activities (e.g., accountant, administrative assistant, statistician).

These descriptions also apply to work environments given the assumption that "the dominant features of an environment reflect the typical characteristics of its members (Holland, 1985, p. 34). Therefore, work environments consist of the distribution of types within them. However, this view is qualified in three ways. First, Holland notes that environments are seldom homogeneous. Second, he argues that sub-units make up an environment (e.g., different departments in an 
organisation). Third, he argues that some individuals within an environment will have more influence over others to shape that environment.

Holland's theory can be summed up by the old adage that birds of a feather flock together. However, this apparently simple idea has been refined through correlational research in order to indicate the way in which the types are related to each other in a closed loop in the following order: realistic, investigative, artistic, social, enterprising, and conventional. Adjacent types are said to be more closely related to one another than those more distant. The theory also includes subtypes in terms of particular combinations of the six personality types that are expressed in terms of a two- or three-type code. For example, an individual is said to be 'consistent' if his or her subtype is comprised of elements that are adjacent to each other. For example, a realistic-investigative person is a consistent subtype in terms of the elements sharing features such as unsociability, and orientation towards things, and self-deprecation. On the other hand, a conventional-artistic individual would be 'inconsistent' given the conflicting elements of this subtype: conformity and originality, control and expressiveness, business and art. If a person has one type which is dominant then he or she is said to be 'differentiated'.

Holland's (1985, p. 5) personality-matching approach hinges on the assumption that people possess a set of interests and attitudes which make up distinct personality types. These interests and attitudes predispose individuals in such a way that they choose to work in environments that are congruent with their personality types. The exact nature of the process involved in choosing a career field is left unspecified in the theory. However, a key feature of this approach is its static nature. Individuals are viewed as possessing relatively fixed personality characteristics with identity being seen in terms of the 'possession of a clear and stable picture of one's goals, interests, and talent'.

\section{Holland's framework and engineering as a career}

Applying Holland's framework to engineering the 'occupation finder' (Holland, 1985) classifies this career area as a 'realistic' occupation. It is therefore said to attract people who primarily perceive themselves as having practical abilities and a preference for working with objects and machines rather than people. The particular sub-type for this occupational group is 'realistic-investigative', with the investigative element being of secondary importance and associated with a preference for problem-solving and an interest in science. There have been a number of studies that have applied Holland's theory of careers to the study of personvocational career fit in academics. Although a full review of research based on 
Holland's model is beyond the scope of this chapter, a brief review provides some context for the investigation that is reported on.

Several studies have examined the role of personality in choices of students in higher education and the importance of person-environment fit (Astin, 1993; Feldman, Smart, \& Ethington, 1999; Porter \& Umbach, 2006; Su et al., 2009). These studies point to achievement in academic and vocational settings being a function of the congruence or fit between personality and the social and physical environments. Person and thing orientations therefore reflect the degree to which people have an interest in the social and physical aspects of their environment (Graziano, Habashi, \& Woodcock, 2011; Little, 1968, 1972). Little (1968) considered people's orientations toward social and physical environments and argued that they differ in how much they are interested in people ('person orientation') or objects in their environment ('thing orientation'). Recent research has indicated that these orientations are not oppositions on a single dimension but rather are independent of one another (Graziano, Habashi, Evangelou, \& Ngambeki, 2012). In other words, people can be high in both, low in both, or high in one and low in the other. Woodcock, Graziano, Branch, Habashi, et al. (2012) conducted a review of fifteen studies that examined person and thing orientations and interest and persistence in engineering. Their analysis indicates that 'thing orientation' is directly and positively associated with an interest in science and engineering. This association has also been found in students within the fields of science and engineering, and higher than students not studying in the areas (Graziano et al., 2012). The engineering students' scores on person and thing orientations suggest that they are more oriented toward things and people rather than oriented to things instead of people (Woodcock, Graziano, Branch, Ngameki, et al., 2012). However, Branch, Woodcock, \& Graziano (2015) found that 'thing orientation' directly predicts research career intentions in engineering.

\section{Method}

Garfinkel (1967) suggests that retrospective accounting for decisions is a common feature of daily life. He argues that decision-making may have little to do with electing a course of action on the basis of available information but rather may be the product of people's ability to define the basis for a decision once made. This type of accounting can therefore be viewed as justifying a course of action and involves "assigning outcomes their legitimate history" (Garfinkel, 1967, p. 114). He therefore poses the counterintuitive notion that "the outcome comes before the decision." The study presented here has adopted this retrospective view of decision-making and in doing so involves two important methodological implications. 
First, attention was required to be directed at individuals who had already made a career choice rather than those who had yet to decide. Second, those involved in the study had to be given an adequate opportunity to account for their choices in terms being given an opportunity to talk at length about their reasoning.

The study focused on undergraduate engineering students at a Scottish university taking these two propositions into account. Students were recruited by direct in-class invitation across all stages of the degree programme with twenty taking part in total. The participants were interviewed using a semi-structured format involving general questions about their choice of engineering as a course and career choice. These interview questions were designed to elicit answers that gave the students an opportunity to talk about themselves and their career interests (e.g. "Tell me about what interested you in engineering"), as well as account for their course choice (e.g. "Why did you decide to study for a degree in engineering?"). With regard to these kinds of questions, degree course choice was taken as a proxy for occupational career choice.

The interviews were transcribed on the basis of readability rather than including para-linguistic features. This was done given that the basis of the analysis was to examine the participants' attempts to produce credible and coherent accounts of their choice of engineering as a career. With regard to the analytic procedure the transcript material was read by taking into account a conversation analytic stance in which both questions and answers were considered in relation to each other as turns at talk. Use was made of Sack's $(1972,1974)$ work on membership categories. Sack noted that persons may be described according to certain membership categories, for example, by occupation. These categories can be drawn from certain conventional collections which Sacks referred to as membership categorisation devices. An important feature of these is that they can be used as a means of ascribing to person activities or characteristics they are conventionally associated with. When a certain category is used by a speaker, the hearer is able to make use of a stock of conventional knowledge about the category and make certain inferences. In interviews concerning career choices these stock of conventional knowledge can be used in order to guide interviewers in how they respond to interviewees, and in turn how interviewees produce the kinds of answers expected so as to produce intelligible responses.

\section{Analysis and discussion}

According to the Holland's typology, engineering comes under the category of a 'realistic' career. It is therefore said to attract people who primarily perceive themselves as having practical abilities and a preference for working with 
objects and machines rather than people. It also involves a secondary characteristic of being 'Investigative' in terms of a preference for intellectual work, problem-solving and an interest in science. An examination of the engineering students' interviews revealed that eleven of the twenty explicitly mentioned technical competencies or an interest in working with machines as the basis for their choice of this career. The interview extract below is illustrative of this kind of response:

\section{ENG9}

Int: Why did you want to enter the field of mechanical engineering?

Resp: Well, it just started off from being an interest when I was young, making models from Mechano kits and mechanical subjects at school. I enjoyed the physics, maths side of it.

$($ Int $=$ Interviewer; Resp $=$ Respondent $)$

This student gives a fairly typical response that appears to be in alignment with Holland's typology in that he appears to indicate a preference for "mechanical subjects at school" (i.e., 'realistic' activities), and then he goes on to mention that he enjoyed 'investigative' related academic subjects.

However, although it was possible to select responses which seemed to offer support for Holland's personality typology it became evident that this could only be achieved by ignoring the complex conversational context of such responses. When this was examined, mismatches between the responses and typology were revealed and categorisation in such a way often became problematic. As the following respondent's answers show, the conversational context in terms of the question-and-answer turns reveals a much more nuanced and variable account:

\section{ENG10}

Int: Why did you want to enter the field of mechanical engineering?

Resp: Well, it's a subject, engineering as a whole is a subject that I've been interested in since a child; building things, seeing how things work, taking things apart. And also there's the influence of my parents; my father is an architect and also my grandfather is an engineer, so there's a sort of family thing. So no matter how much you try to get away from it, you are influenced by what your parents do. But generally from an early age I was interested in machines and it stemmed from there. 
(2)

Int: How did you arrive at your particular decision to aim for this occupation?

Resp: Em, well funnily enough, I did a year of architecture before starting here. I was always interested in building something, design, that sort of area, construction. So I tried architecture and discovered that midway through that year that I wasn't interested in it. So I completed the year and came here.

In interview extract (1) the respondent links an interest in the practical activities engaged in as a child ("building things and taking things apart") with an interest in machines. This appears to be a straightforward instance of a 'realistic' personality type. However, in extract (2) the same interest is associated with his earlier choice of architecture. "Building things" and "construction" are now associated with an interest in architecture. Yet, Holland classifies architecture under 'artistic' personality type occupations, a type which is unrelated to engineering. In this regard the conversational nature of the interview reveals a much more elaborate account that cannot so easily pigeon-hole the respondent as a particular personality type.

A more serious problem for Holland's typology is the appearance of responses that are contradictory and so cannot be categorised. The following example illustrates this kind of contradiction.

\section{ENG7}

Int: Why did you want to enter the field of mechanical engineering?

Resp: I didn't fancy doing a desk job, well primarily a desk job like an accountant $\ldots$ and I liked technical subjects at school and so engineering seemed suitable.

Int: I'd like you move on to your placements. What sort of expectations did you have about them?

Resp: The first placement was basically maintenance engineering and it was good hand-on experience. The second placement, that was a bit more professional. That was a desk job doing the development of products and that was more my idea of what a professional engineer would do, and that's the kind of thing I see myself doing.

In interview extract (1) the respondent provides an answer that seems to indicate evidence of a dominant 'realistic' trait; a preference for technical subjects and an aversion for a "desk job." However, interview extract (2) while his first pla- 
cement is presented as being good "hands on experience," he clearly expresses a preference for a "desk job" which contradicts what he had said about this type of occupation in extract (1).

In other instances there were more subtle forms of contradiction that can be traced through the interview conversation where providing accountability for career choice is dispersed across several turns.

\section{ENG1}

(1)

Int: Why do you want to enter the field of mechanical engineering?

Resp: My dad is a marine engineer and I've worked with him during the summer holidays and I enjoyed it, and I'd also like to be sitting at a desk some of the time designing things.

Int: What sort of work were you doing?

Resp: Stripping engines and more heavy work.

Int: And when you say sitting down what sort of work would you be doing?

Resp: Designing mainly.

Int: When you finish the course what area do you hope to go into?

Resp: Probably design.

Int: You mentioned design, what's appealing about design work?

Resp: You're using your mind to design.

These interview extracts trace a shift in the presentation of the respondent's occupational interests. In interview extract (1) mention is made of enjoying manual work and an interest in design. This response appears to accord with Holland's 'realistic-investigative' personality type for engineering. However, extracts (2) and (3) indicate preferences for design work which involves "using your mind." These responses might therefore be interpreted as showing signs of a dominant 'investigative' trait. Again, we see that the conversational context is important and that responses cannot be simply taken out of this context and made to fit into Holland's career personality typology.

Indeed, many of the respondents appeared to provide responses that when taken out of the interview interactional context, could be taken as indicating 'investigative' types. The key to understanding these responses is the nature of the questions asked which set up the type of response expected in terms of providing an 
intelligible answer that fits. Nine of the twenty participants expressed an interest in physical sciences or mathematics, or spoke in terms of problem solving as the basis for their choice of engineering. The following examples illustrate this kind of response.

\section{ENG 2}

Int: Why do you want to enter the field of mechanical engineering?

Resp: Em, I don't know, I just always enjoyed science subject at school. Physics was always my favourite and I wanted something to do with physics.

\section{ENG 8}

Int: What is it that draws you to this area, you could say this is what I like doing, this is what mechanical engineering is about?

Resp: Finding out about things.

\section{ENG 5}

Int: What was it that drew you to engineering, what was it you liked about it?

Resp: It's not so much I like engineering as I hated the arts subjects more if you understand what I mean. It wasn't a second choice, I do like it but I don't know why. The thought never occurred to me, I just like maths I suppose, I like problem solving.

These responses give prominence to a school subject-based interest as well as problem solving. All are expressed in terms of respondents likes as a baseline level for their career choice. This is interesting from the point of view that, although do not present as a 'realistic' personality type on first sight, the do nonetheless offer accounts that are rooted in a dispositional discourse. It is easy to see why this is the case given that the questions asked are framed in personal terms and therefore demand a corresponding answer that reflexively fits this framing. Moreover, these types of accounts are difficult to challenge given that career choice is expressed in terms of accountability through basically saying "this is how I am."

Despite the problems of categorising responses as fully in accordance with Holland's typology, the transcript material could be argued to lend some degree of support for it. The engineering students did after all refer to interests that offered some support for reading into the data 'realistic' and 'investigative' traits. It could therefore be argued that there are indeed underlying personality traits present. However, it is possible to consider these responses as the articulation of conventional knowledge associated with the membership category of engineer as an occupation, or in Sack's $(1972,1974)$ terms, membership categorisation devices. It must be stressed that these categories, although stocks of conventional knowledge, are 
nevertheless linguistic devices used in the accomplishment of intelligibility and deployed by speakers within the nature of the interactional context. Holland draws attention to the stereotypical nature of people's perception of careers claiming that "our everyday experience has generated a sometimes inaccurate but apparently useful knowledge of what people in various occupations are like" $(1985$, p. 9). He points out that were this not so, interest inventories which are based on these stereotypes would have little validity.

Undoubtedly, shared bodies of knowledge about different occupations exist. However, we have seen that respondents can package this kind of knowledge in creative ways that cannot be predicted from the knowledge base itself, but only from a detailed examination of the sequential nature of the conversational turns.

The question remains, why do respondents draw upon these membership categorisation devices when talking about their own career choices? An answer to this question can be found by looking at the differences in the sequences of talk between those who use these kind of responses early in the interview and those who do not. Consider the juxtaposition of the following pair of interview extracts from different students on the engineering degree programme. In the case of the first extract, which has already been referred to earlier on, the full conversational turns are now given.

\section{ENG 9}

Int: Why did you want to enter the field of mechanical engineering?

Resp: Well, it just started off from being an interest when I was young, making models from Mechano kits and mechanical subjects at school. I quite enjoyed them, I enjoyed the physics, maths side of it. I wasn't certain I wanted to do mechanical engineering, there's civil, electrical and chemical. I had a look around and just decided to come to the mechanical course.

Int: Do you think there are particular qualities required to be a mechanical engineer?

\section{ENG 6}

Int: Why did you want to enter the field of mechanical engineer?

Resp: Well, my brothers all did engineering so I was kind of led onto that when I left school. I'd always been interested in engineering, cars and stuff like that so it was just there wasn't any other option and I just went straight into it. I wasn't really thinking career-wise what particular area I wanted to go into, it was more or less it was engineering or nothing else.

Int: When you say there was nothing else, why did that arise then? Did they talk to you, or did you feel that this was the right area for you? 
Resp: Well, it was the right area for me anyway and I'd thought of other careers, you know, you go through the range of them, and engineering seemed to be the only reasonable one because I took to it quite naturally.

Int: Did your brothers tell you what it was about?

Resp: Well I had a fair idea. I realise now that I was a bit limited in my knowledge of what it covered, the whole range of subjects it covered, you know, thermodynamics and that sort of stuff. And most of the subjects aren't that interesting, there's only a few specialist subjects that I find interesting. But if I had done something different, say civil or electrical or something like that I knew I wouldn't be happy as I am now because I don't find electrical that interesting and it's difficult to understand, similar with civil.

Int: What is it that draws you to mechanical as opposed to electrical or civil?

The first interview extract is an example of what can be termed a standard membership category account for choosing engineering as a career. The response displays a common sense knowledge of the characteristics associated with engineering; knowledge which Holland has put to use in his occupational personality typology. Respondent ENG 9 mentions the 'realistic' and 'investigative' elements of an engineer: an interest in construction kits and mechanical subjects at school, and an interest in the sciences. Note how once this response is given, the interviewer begins a new line of questioning about the qualities associated with being an engineer. In other words, the line of questioning moved away from the interviewee's choice of career towards talking about the occupation in a general sense. This short conversation in establishing the nature of the interviewee's career choice can be contrasted with the more protracted question and answer turns in the second interview extract. Respondent ENG 6 begins by talking about his brothers doing engineering and how he was "led on to" this field on leaving school. He states that "it was more or less it was engineering or nothing else" and the interviewer subsequently picks up on this remark by asking "When you say there was nothing else, why did that arise then? Did they talk to you, or did you feel that this was the right area for you?" Notice the reference to "they" which is also going back to the interviewee's mention of "all" his brothers doing engineering. This question is, in effect, testing the extent to which the interviewee has been influenced by family members in his choice of engineering. In response, the interviewee attempts to portray his choice of engineering as involving his disposition to it ("it was the right area for me.....engineering seemed to be the only reasonable one because I took to it quite naturally"). However, he does not draw upon the standard membership category for this occupation in terms of mentioning an interest in working with machines or science subjects). Given that this kind of account is not forthcoming, the interviewer is more direct in seeking to test the extent to which the interviewee was influenced in his decision ("Did your brothers tell you what 
it was about?"). In response the interviewee still does not draw upon the standard membership category account but instead talks about his understanding of engineering sub-areas and what he is not interested in ("I realise now that I was a bit limited in my knowledge of what it covered......,if I had done something different, say civil or electrical or something like that I knew I wouldn't be happy"). The interviewer picks up on this response and is still pursuing the standard membership category account ("What is it that draws you to mechanical as opposed to electrical or civil?"). The question is posed in terms of personal linkage between the interviewee and mechanical engineering.

What can be seen in this extended question and answer sequence is a reflexive analysis of the researcher's (interviewer) own pursuance of the standard membership category, or Holland's terms the 'realistic' and 'investigative' dimensions. Interviewees who give this kind of account at the outset and not pursued further while those who do not and instead mention family members who are engineers, or who talk in general terms about their interest in engineering, are questioned further in order to establish their 'personality fit' with the occupation. Giving the standard membership category account is therefore a foundational type of answer. It acts as a way of displaying an intelligible answer that is not subject to further challenge in that explicitly draws attention to the person-career fit. Therefore, this kind of account in a sense engineers an occupational identity in the there and then of the interaction and in so doing is an effective response.

\section{Conclusion}

The analysis and discussion of the interview extracts presented above demonstrates the explanatory power of focusing on the ways in which career choice, when asked about as a 'choice', is accounted for within conversational turns. As Harper, Randall and Sharrock (2016, pp. 204-209) argue, reasons are not causal in relation to choices but rather are embedded within different language games (Wittgenstein, 1953) and bound up with reasoning as cultural knowledge. Interview participants through their question and answer turns display to one another this cultural reasoning in relation to framing their course of action as a 'career choice' bound up with their own disposition.

This understanding of career choice does not seek to remove the nature of a 'choice' from the interactional context in terms of being a 'decision' linked to a personality type. Holland's personality matching approach, although derived from psychometric testing, can be considered in another way in the context of talk-in-interaction. Instead of treating responses as revealing something about 
respondents' personalities, this study offers an altogether different proposition, one that to use Garfinkel's (1967) term 'sense-able' accounts. This perspective allows the researcher to examine how personality-expressive responses are related to issues of intelligibility and accountability. It also allows the researcher to study whole conversational patterns rather than selected aspects which seem to fit a personality matching model when abstracted out. Holland's approach engineers a personality typology that draws upon common sense reasoning about there being 'right' types and 'wrong' types for career occupations. However, occupational identities are engineered in situ by drawing on standard membership categorisations within interactional the context of questions being asked that require a career choice account that displays credible reasoning.

\section{References}

Astin, A. W. (1993). What Matters in College: Four Critical Years Revisited. San Francisco, CA: Jossey-Bass.

Branch, S. E., Woodcock, A., \& Graziano, W. G. (2015). Person orientation and encouragement: Predicting interest in engineering research. Journal of Engineering Education, 104(2), 119-138.

Feldman, K. A., Smart, J. C., \& Ethington, C. A. (1999). Major field and person environment fit: Using Holland's theory to study change and stability of college students. Journal of Higher Education, 70, 642-669.

Garfinkel, H. (1967). Studies in Ethnomethodology. Englewood Cliffs, NJ: Prentice Hall.

Graziano, W. G., Habashi, M. M., \& Woodcock, A. (2011). Exploring and measuring differences in person-thing orientation. Personality and Individual Differences, 51, 28-33.

Graziano, W. G., Habashi, M.M., Evangelou, D., \& Ngambeki, I. (2012). Orientations and motivations: Are you a "people person," a "thing person," or both? Motivation and Emotion, 36, 465-477.

Harper, R., Randall, D., \& Sharrock, W. (2016). Choice: The Sciences of Reason in the $21^{\text {st }}$ Century: A Critical Assessment. Cambridge: Polity.

Holland, J. L. (1959). A theory of vocational choice. Journal of Counselling Psychology, $6(1), 35$.

Holland, J. L. (1966). A psychological classification scheme for vocations and major fields. Journal of Counselling Psychology, 13(3), 278.

Holland J. L. (1973). Making Vocational Choices: A Theory of Careers. Englewood Cliffs, NJ: Prentice-Hall.

Holland, J. L. (1985). Making Vocational Choices: A Theory of Vocational Personalities and Work Environments. (2 ${ }^{\text {nd }}$ Ed.) Englewood Cliffs, NJ Prentice-Hall.

Holland, J. L. (1997). Making Vocational Choices: A Theory of Vocational Personalities and Work Environments (3rd ed.). Odessa, FL: Psychological Assessment Resources. 
Little, B. R. (1968). Psychospecialization: Functions of differential orientation towards persons and things. Bulletin of the British Psychological Society, 21, 113.

Little, B. R. (1972). Psychological man as scientist, humanist and specialist. Journal of Experimental Research in Personality, 6, 95-118.

Porter, S. R. \& Umbach, P. D. (2006). College major choice: An analysis of person environment fit. Research in Higher Education, 47, 429-449.

Sacks, H. (1972). On the analyzability of stories by children. Directions in Sociolinguistics, 325-345.

Sacks, H. (1974). On the Analyzability of Stories by Children. In R. Turner (Ed.), Ethnomethodology, (pp. 216-232). Harmondsworth: Penguin.

Su, R., Rounds, J., \& Armstrong, P. I. (2009). Men and things, women and people: A meta-analysis of sex differences in interests. Psychological Bulletin, 135, 859-884.

Wittgenstein, L. (1953). Philosophical Investigations (G. E. M. Anscombe \& G. H. von Wright Trans.). Oxford: Blackwell.

Woodcock, A., Graziano, W. G., Branch, S. E., Ngambeki, I., \& Evangelou, D. (2012). Engineering students' beliefs about research: sex differences, personality, and career plans. Journal of Engineering Education, 101, 495-511. 